This item was submitted to Loughborough's Research Repository by the author.

Items in Figshare are protected by copyright, with all rights reserved, unless otherwise indicated.

\title{
Noise and vibration from high-speed trains
}

PLEASE CITE THE PUBLISHED VERSION

http://dx.doi.org/10.1680/navfht.29637

\section{PUBLISHER}

(c) V. V. Krylov and Thomas Telford Limited

\section{VERSION}

VoR (Version of Record)

\section{LICENCE}

CC BY-NC-ND 4.0

\section{REPOSITORY RECORD}

Krylov, Victor V.. 2012. "Noise and Vibration from High-speed Trains". figshare.

https://hdl.handle.net/2134/10014. 
This item was submitted to Loughborough's Institutional Repository (https://dspace.lboro.ac.uk/) by the author and is made available under the following Creative Commons Licence conditions.

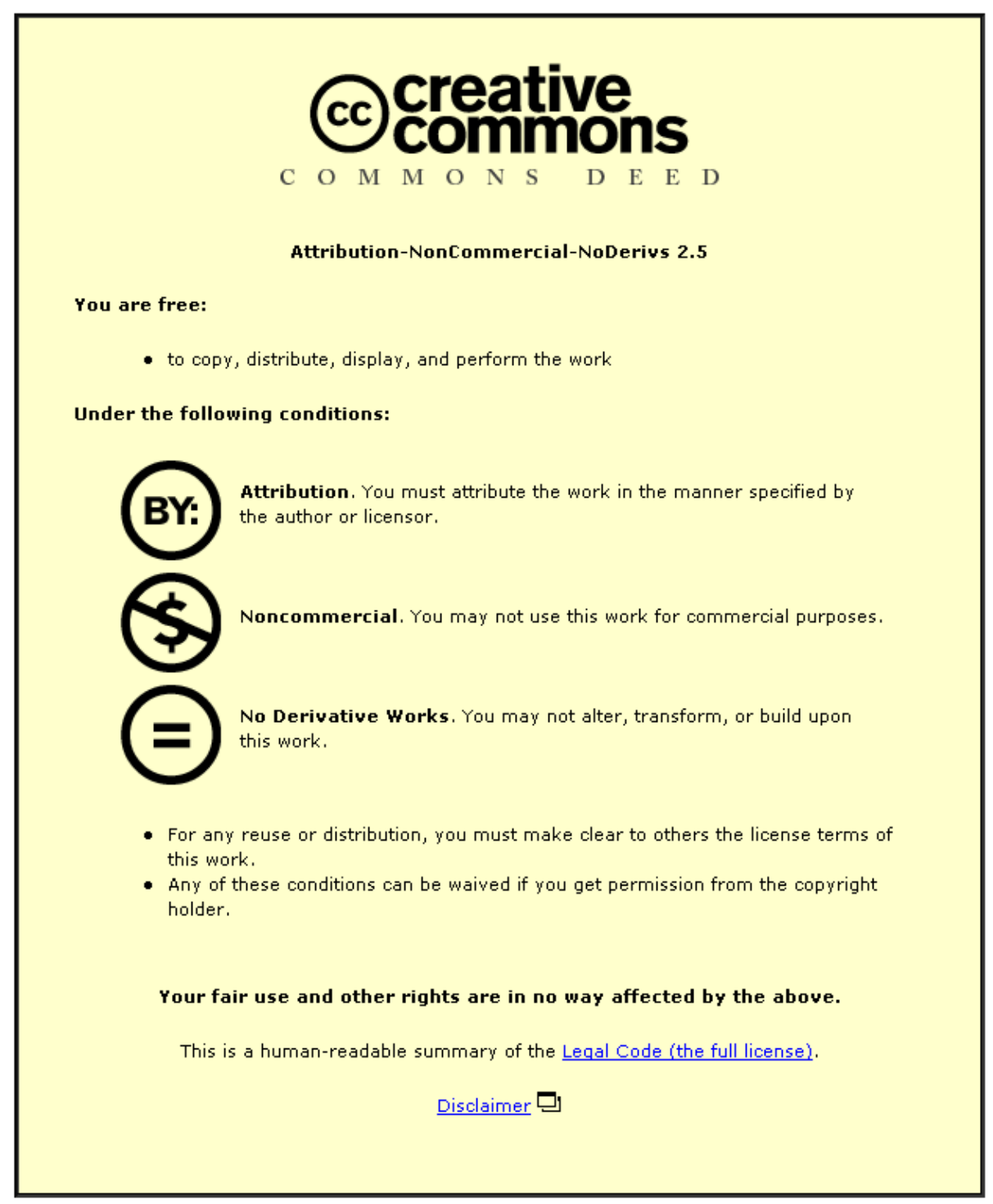

For the full text of this licence, please go to: http://creativecommons.org/licenses/by-nc-nd/2.5/ 


\section{Noise and vibration from high-speed trains}

Edited by

\section{V. Krylov}

Department of Civil and Structural Engineering

Nottingham Trent University

【 Thomas Telford 
Published by Thomas Telford Publishing, Thomas Telford Ltd, 1 Heron Quay, London E14 4JD

URL: http://www.t-telford.co.uk

Distributors for Thomas Telford books are

USA: ASCE Press, 1801 Alexander Bell Drive, Reston, VA 20191-4400

Japan: Maruzen Co. Ltd, Book Department, 3-10 Nihonbashi 2-chome, Chuo-ku, Tokyo 103

Australia: DA Books and Journals, 648 Whitehorse Road, Mitcham 3132, Victoria

First published 2001

A catalogue record for this book is available from the British Library ISBN: 0727729632

(C) V. V. Krylov and Thomas Telford Limited 2001

All rights, including translation, reserved. Except as permitted by the Copyright, Designs and Patents Act 1988, no part of this publication may be reproduced, stored in a retrieval system or transmitted in any form or by any means, electronic, mechanical, photocopying or otherwise, without the prior written permission of the Publishing Director, Thomas Telford Publishing, Thomas Telford Ltd, 1 Heron Quay, London E14 4JD

This book is published on the understanding that the authors are solely responsible for the statements made and opinions expressed in it and that its publication does not necessarily imply that such statements and/or opinions are or reflect the views or opinions of the publishers. While every effort has been made to ensure that the statements made and the opinions expressed in this publication provide a safe and accurate guide, no liability or responsibility can be accepted in this respect by the authors or publishers

Typeset by Helius, Brighton

Printed and bound in Great Britain by MPG Books, Bodmin 


\section{Contents}

Preface

xi

Part 1. Generation and propagation of railway noise

1. Theory of generation of wheel/rail rolling noise

D. J. Thompson

1.1. Introduction 3

1.2. Wheel dynamics 6

1.2.1. Modes of vibration of a railway wheel 6

1.2.2. Frequency response functions 9

$\begin{array}{ll}\text { 1.2.3. Effects of rotation } & 10\end{array}$

1.3. Track dynamics 11

1.3.1. Models for track vibration $\quad 11$

$\begin{array}{ll}\text { 1.3.2 Frequency response functions } & 11\end{array}$

\begin{tabular}{ll} 
1.3.3. & Propagation along the track \\
\hline
\end{tabular}

$\begin{array}{ll}\text { 1.3.4. } & \text { Sleeper response } \\ 13.5 . & 13\end{array}$

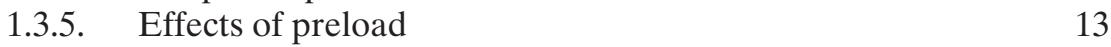

$\begin{array}{ll}\text { 1.4. Roughness and interaction } & 14\end{array}$

1.4.1. Equations of wheel/rail interaction 14

1.4.2. Contact receptances 15

1.4.3. Wheel and rail roughness 16

1.4.4. Roughness modification at the contact zone 17

1.4.5. Effective damping of a rolling wheel 18

$\begin{array}{ll}\text { 1.5. Radiation of sound } & 18\end{array}$

$\begin{array}{ll}\text { 1.5.1. Radiation from the wheel } & 18\end{array}$

$\begin{array}{ll}\text { 1.5.2. } & \text { Radiation from the rail } \\ \text { 1.5.3. } & 20\end{array}$

$\begin{array}{ll}\text { 1.5.3. Radiation from the sleepers } & 21\end{array}$

$\begin{array}{ll}\text { 1.5.4. Aerodynamic sources } & 21\end{array}$

1.5.5. Contribution of various sources $\quad 22$

$\begin{array}{ll}\text { 1.6. Validation } & 23\end{array}$

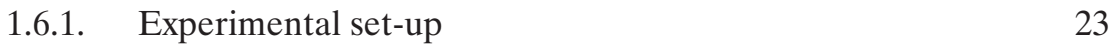

$\begin{array}{lll}\text { 1.6.2. } & \text { Results } & 23\end{array}$

1.6.3. Sine wheel tests 25

1.7. Summary 25

1.8. References 25 
2. Wheel and rail excitation from roughness

P. J. Remington

2.1. Introduction

2.2. Roughness modelling 29

2.2.1. Average roughness model 31

2.2.2. Distributed point-reacting spring model 33

2.2.3. Full elastic-interaction model $\quad 40$

2.3. Roughness measurement 45

2.3.1. Accelerometer-based devices 45

2.3.2. Displacement-based devices 46

2.4. Wheel and rail roughness characteristics 48

2.5. Controlling wheel/rail noise at the source 53

2.5.1. Roughness amplitude reduction $\quad 54$

2.5.2. Contact stiffness reduction and contact area increase $\quad 56$

2.6. Summary and conclusions $\quad 61$

2.7. References 62

3. High-speed train noise barrier tests at reduced scale $\quad 65$

J. D. van der Toorn

3.1. Modelling outdoor sound propagation 65

3.2. Scale modelling $\quad 65$

3.2.1. Similarity $\quad 65$

3.2.2. Measurable quantities $\quad 66$

3.2.3. Sound sources $\quad 66$

$\begin{array}{ll}\text { 3.2.4. Receiver } & 70\end{array}$

3.2.5. Atmospheric absorption $\quad 70$

$\begin{array}{ll}\text { 3.2.6. Ground plane } & 71\end{array}$

$\begin{array}{lll}\text { 3.2.7. } & \text { Barriers } & 73\end{array}$

3.3. Scale modelling of railway noise $\quad 73$

3.3.1. An acoustical 1:32 scale model of a high-speed train 73

3.3.2. An acoustical 1:32 scale model of a railway track 75

3.4. Design of sound-absorbing barriers at a scale of 1:32 76

3.4.1. Reference absorption curve $\quad 76$

3.4.2. Absorption extracted from excess attenuation 79

$\begin{array}{ll}\text { 3.5. } & \text { Barrier tests } \\ \text { 3.6. } & 79\end{array}$

3.6. Concluding remarks 81

3.7. Acknowledgements 82

3.8. References 82

4. Generic prediction models for environmental railway noise $\quad 85$

J. J. A. van Leeuwen

4.1. Introduction 85

4.2. Noise indicators 85

4.2.1. Annoyance 85

4.2.2. The noise level and the A-frequency-weighted noise level 86 
4.2.3. Root mean square average 86

4.2.4. The maximum sound level $L_{\mathrm{A}, \max } \quad 87$

4.2.5. The long-time average sound level and the equivalent $\begin{array}{ll}\text { sound level } & 87\end{array}$

$\begin{array}{lll}\text { 4.2.6. } & \text { Statistical indicators } & 87\end{array}$

4.2.7. The basic indicators: $L_{\mathrm{A}, \text { day }}, L_{\mathrm{A} \text {, evening }}, L_{\mathrm{A} \text {, night }}$ and $L_{\mathrm{A}, 24 \mathrm{~h}}$

4.2.8. The composite indicator $L_{\mathrm{den}} \quad 88$

4.3. Background to environmental-noise predictions 88

4.3.1. Why noise predictions? 88

4.3.2. Noise predictions for where? $\quad 88$

4.3.3. What do we want to calculate? $\quad 89$

4.3.4. When to use prediction models $\quad 91$

4.3.5. How do you provide your input? 92

4.3.6. Sequence of noise predictions 93

4.4. What is a noise prediction model? 94

4.5. Noise prediction methodology 95

4.6. Source description model 96

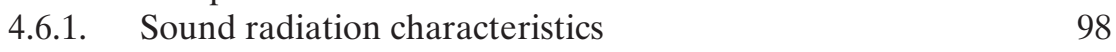

$\begin{array}{lr}\text { 4.7. Propagation models } & 98\end{array}$

4.7.1. Geometrical spreading $\quad 100$

4.7.2. Atmospheric absorption 101

4.7.3. Absorption by the ground 101

4.7.4. Attenuation due to a barrier or another obstacle 102

4.7.5. Additional types of attenuation 104

4.7.6. Reflections 105

4.7.7. Meteorological correction 105

4.8. Calculation of the noise level 106

4.8.1. Calculating the noise level with monopole or dipole noise sources 107

4.9. The determination of the sound propagation paths 109

4.10. Accuracy of a generic prediction model 112

4.11. Conclusions 113

$\begin{array}{ll}\text { 4.12. References } & 114\end{array}$

$\begin{array}{lll}\text { Part 2. Measurements and control of railway noise } & 117\end{array}$

5. Measurements of railway noise 119

M. T. Kalivoda

5.1. Introduction 119

$\begin{array}{ll}\text { 5.2. Exterior noise } & 120\end{array}$

5.2.1. Diagnostics 122

5.2.2. Type testing 126

5.2.3. Monitoring 144

5.2.4. Non-acoustic factors influencing exterior rail noise 149

$\begin{array}{ll}\text { 5.3. Interior noise } & 158\end{array}$

$\begin{array}{ll}\text { 5.3.1. Diagnostics } & 158\end{array}$

$\begin{array}{ll}\text { 5.3.2. Type testing } & 160\end{array}$

5.4. References 160 
6. Means of controlling rolling noise at source

C. J. C. Jones and D. J. Thompson

6.1. Introduction 163

$\begin{array}{ll}\text { 6.2. Wheel noise } & 164\end{array}$

6.2.1. Damping treatments 164

6.2.2. Wheel shape optimization 166

$\begin{array}{lll}\text { 6.2.3. } & \text { Resilient wheels } & 168\end{array}$

$\begin{array}{ll}\text { 6.2.4. } & \text { Reduced wheel radiation } \\ \text { Track noise } & 169\end{array}$

$\begin{array}{ll}\text { 6.3. Track noise } & 170\end{array}$

\begin{tabular}{ll} 
6.3.1. & Rail pad stiffness \\
\hline
\end{tabular}

$\begin{array}{ll}\text { 6.3.2. Damping treatments } & 173\end{array}$

\begin{tabular}{ll} 
6.3.3. & Rail shape optimization \\
\hline
\end{tabular}

$\begin{array}{lll}\text { 6.3.4. } & \text { Track mobility } & 176\end{array}$

6.3.5. Ballastless track forms 177

$\begin{array}{ll}\text { 6.4. Roughness } & 177\end{array}$

6.4.1. Effects of braking system 177

$\begin{array}{ll}\text { 6.4.2. Rail corrugation } & 179\end{array}$

6.4.3. Changes to the contact zone 180

$\begin{array}{ll}\text { 6.5. Shielding } & 180\end{array}$

6.6. Measures in combination 180

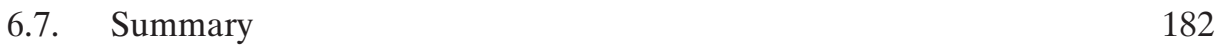

6.8. References 182

Part 3. Bursting noise associated with non-linear pressure waves in tunnels 185

7. Micropressure waves radiating from a Shinkansen tunnel portal $\quad 187$

T. Maeda

$\begin{array}{ll}\text { 7.1. Introduction } & 187\end{array}$

7.2. Generation of a compression wave by a train 189

7.3. The propagation of the compression wave through the tunnel 192

7.4. Radiation of the micropressure wave out of the tunnel portal 198

7.5. Measures to decrease the micropressure waves 203

7.5.1. Measures applied to Shinkansen tunnels 204

7.5.2. Measures applied to Shinkansen trains 206

$\begin{array}{lll}\text { 7.6. } & \text { References } & 210\end{array}$

8. Emergence of an acoustic shock wave in a tunnel and a concept of shock-free propagation

N. Sugimoto

8.1. Introduction 213

8.2. Overview of the problem 216

8.3. Analysis of the near field 219

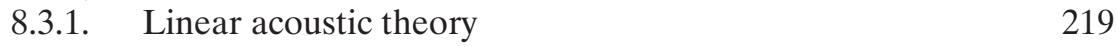

8.3.2. Evaluation of the pressure field 220 
8.4. Analysis of the far field 223

8.4.1. Formulation 223

8.4.2. Non-linear wave equation for the far field 226

8.4.3. Evolution of the pressure wave into a shock 228

$\begin{array}{ll}\text { 8.5. Shock-free propagation } & 229\end{array}$

8.5.1. Linear dispersion characteristics $\quad 229$

8.5.2. Effects of the array of Helmholtz resonators 234

8.5.3. Suppression of shock formation 236

8.6. Experimental verification 241

8.6.1. Experimental set-up 241

8.6.2. Experimental results 243

$\begin{array}{ll}\text { 8.7. Conclusion } & 244\end{array}$

8.8. References 245

Part 4. Generation of ground vibrations by surface trains 249

9. Generation of ground vibration boom by high-speed trains 251

V. V. Krylov

9.1. Introduction 251

9.2. Quasi-static pressure mechanism of generating ground vibrations 252

9.2.1. Dynamic properties of the track 253

9.2.2. Forces applied from sleepers to the ground 255

9.3. Green's function for the problem 256

9.3.1. Homogeneous elastic half-space 257

9.3.2. Effect of layered ground structure 258

9.4. Calculation of generated ground vibrations 262

9.4.1. Vibrations from a single axle load 262

9.4.2. Vibrations from a complete train 262

9.5. Trans-Rayleigh trains 263

9.5.1. General discussion 263

9.5.2. Ground vibrations from TGV and Eurostar trains 265

9.5.3. High-speed trains travelling underground 270

9.5.4. Waveguide effects of embankments on generated
ground vibration fields 277

9.6. Conclusions 281

9.7. Acknowledgements 282

$\begin{array}{ll}\text { 9.8. References } & 282\end{array}$

10. Free-field vibrations during the passage of a high-speed train: experimental results and numerical predictions

G. Degrande

10.1. Introduction 285

10.2. The in situ measurements 287

$\begin{array}{ll}\text { 10.2.1. The train } & 287\end{array}$

10.2.2. The track 288 
10.2.3. The soil 288

10.2.4. The experimental set-up 290

10.3. Experimental results 291

10.3.1. The passage of a Thalys HST at a speed $v=314 \mathrm{~km} / \mathrm{h} \quad 291$

10.3.2. The influence of the train speed 293

10.4. Krylov's analytical prediction model 298

10.4.1. The force transmitted by a sleeper due to a single axle load 300

10.4.2. The forces transmitted by all sleepers due to a train passage 301

10.4.3. Response of the soil 302

10.5. Analytical predictions 303

10.5.1. Track response 303

10.5.2. Green's functions 305

10.5.3. Free-field response 306

$\begin{array}{ll}\text { 10.6. Conclusion } & 312\end{array}$

10.7. Acknowledgements 313

10.8. References 313

11. High-speed trains on soft ground: track-embankment-soil response and vibration generation

C. Madshus and A. M. Kaynia

11.1. Introduction 315

11.2. Case study 315

11.2.1. Test site and test programme $\quad 317$

11.2.2. Observations $\quad 317$

11.3. Measurements 323

11.4. Dynamic properties of soil and embankment materials 326

11.5. Numerical simulation 333

11.5.1. Simulations and comparisons $\quad 336$

$\begin{array}{ll}\text { 11.6. Countermeasures } & 337\end{array}$

11.7. Physical model 339

11.8. Environmental vibration $\quad 342$

11.9. Conclusions 343

11.10. Acknowledgements 344

$\begin{array}{ll}\text { 11.11. References } & 344\end{array}$

12. Ground vibrations alongside tracks induced by high-speed trains: prediction and mitigation

H. Takemiya

12.1. Introduction $\quad 347$

12.2. Basic theory 349

12.2.1. Solution method for a moving load 349

12.2.2. Track-ground dynamic interaction 351

12.2.3. Modelling of a loading by train 354

12.2.4. Ground vibration due to a quasi-static moving load 355

12.2.5. Elastodynamic analysis 357 
12.3. Features of the response for a moving load 363

12.3.1. Dispersion characteristics of layers 363

12.3.2. Transient responses 364

12.3.3. Ground surface motions 374

12.3.4. Response of track-ground system 375

12.4. Field measurements, theoretical prediction and mitigation $\quad 377$

12.4.1. Measurement data 377

12.4.2. Wave propagation at the site 380

12.4.3. Prediction of ground motions 383

12.4.4. Vibration mitigation measures - WIBs 385

$\begin{array}{ll}\text { 12.5. Conclusion } & 387\end{array}$

12.6. Appendix: layer stiffness matrix 389

12.6.1. The layer stiffness matrix with respect to stresses acting on the $z$ plane $\left\{\begin{array}{lll}\sigma_{12} & \sigma_{22} & \sigma_{32}\end{array}\right\}$

12.6.2. The stiffness matrix for a half-space with respect to stresses acting on the $z$ plane $\quad 391$

12.7. References

Part 5. Ground vibrations generated by underground trains

13. Prediction and measurements of ground vibrations generated from tunnels built in water-saturated soil

S. A. Kostarev, S. A. Makhortykh and S. A. Rybak

13.1. Introduction 397

13.2. Waves radiated by a cylindrical oscillating shell 398

13.3. Transmission of vibrations to the ground surface 405

13.4. Two-level elastic system for vibration reduction 407

13.5. Method of estimation of the elastic parameters and damping of layered ground 411

13.6. Discussion 418

13.7. Acknowledgements 421

13.8. References 421

14. Measures for reducing ground vibration generated by trains in tunnels 423 H. E. M. Hunt

14.1. Introduction 423

14.2. Tunnels with floating slabs $\quad 424$

14.3. Vibration from railway tunnels $\quad 425$

14.4. Conclusions $\quad 430$

14.5. References 430 


\section{Preface}

During the last decade, high-speed railways have become one of the most advanced and fast-developing branches of transportation. The reasons for this are the relatively low air pollution per passenger, compared with road vehicles, and the very high speeds achievable by the most advanced modern trains-French TGV, Eurostar, Thalys, the German ICE, British high-speed trains, the Italian Pendolino, the Swedish X2000, the Japanese Shinkansen, etc. For example, for French TGV trains a maximum speed of more than $515 \mathrm{~km} / \mathrm{h}$ was achieved in May 1990, and speeds close to $300 \mathrm{~km} / \mathrm{h}$ are now typical for commercially used TGV and Eurostar trains. Prospective plans for the year 2010 assume that the New European Trunk Line will have connected Paris, London, Brussels, Amsterdam, Cologne and Frankfurt by a high-speed railway service that will provide fast and more convenient passenger communications within Europe. Similar plans are being developed in the USA and Japan. All these make high-speed railways increasingly competitive with air and road transport at short and medium distances.

Unfortunately, when train speeds increase, the intensity of railway-generated noise and vibration generally becomes higher. And this represents a major environmental problem for nearby residents, schools and hospitals. Railway operators and local authorities need to be familiar with those new aspects of railway noise and vibration which are associated with high-speed trains. Almost all known mechanisms of generation of railway noise and vibration are speed dependent. These include both wheel/rail rolling noise and aerodynamic noise, the latter being important for train speeds higher than $300 \mathrm{~km} / \mathrm{h}$. This applies even more so for generated ground vibrations. For example, when train speeds exceed certain critical velocities of elastic waves propagating in the ground or in the track/ground system, new mechanisms of generation of ground vibrations may appear, in addition to those already known for conventional trains. In particular, a very large increase in generated ground vibrations may occur if train speeds exceed the velocity of Rayleigh surface waves in the ground. If this happens, a ground vibration boom takes place, similar to the sonic boom normally associated with supersonic aircraft. The first observation of a ground vibration boom took place on the recently opened highspeed railway line in Sweden. This line was built on very soft soil, with Rayleigh wave velocities as low as $45 \mathrm{~m} / \mathrm{s}$. This is why an increase in train speed from 140 to 
$180 \mathrm{~km} / \mathrm{h}$ was sufficient for the phenomenon to be observed, thus indicating that 'supersonic' or (more precisely) 'trans-Rayleigh' trains have become today's reality.

There are many other new physical effects and mechanisms of generation of noise and vibration which are specific to high-speed trains, for example the effects of traininduced non-linear pressure wave propagation in long tunnels, resulting in bursting noise radiated from the exit tunnel portals. In addition to these new effects, the 'traditional' mechanisms of generation of railway noise and vibration and their propagation from the source to a receiver demonstrate interesting new features and sometimes behave in a different way as train speeds increase. An example of this may be seen in the design of noise barriers for high-speed railway lines. Such barriers should take into account the spatial redistribution of noise generation mechanisms as train speeds increase.

Although some of the problems of noise and vibration from high-speed trains are being addressed in an increasing number of journal papers and conference proceedings, there is still no general reference book which could help a reader starting to study this problem to find answers to numerous theoretical and practical questions. The existing reviews concerning railway-generated noise and vibration deal largely with conventional trains and do not reflect specific high-speed problems. The present book, which consists of 14 chapters grouped into five parts, aims to fill this gap. It represents the views of leading international experts on the current status of the problems of generation and propagation of noise and vibration from high-speed trains and suggests possible ways of reducing their environmental impact. The book describes mainly the results of recent academic research and is pitched largely at an advanced level. In the light of this, it is assumed that the ideal reader will have a university background in engineering, physics or applied mathematics. At the same time, several chapters of the book have been written by railway noise and vibration practitioners. These chapters contain a lot of experimental data with interesting illustrations and can be understood by a less wellprepared audience.

The intended readership of the book is rather wide. It includes scientists and engineers working on the prediction and remediation of railway noise and vibration, environmental consultants investigating particular situations associated with the environmental impact of railways, local authorities, designers of new railway lines, etc. The book will also be useful to university students, railway enthusiasts and for members of the general public concerned with topical environmental issues.

Victor V. Krylov 